\title{
Results and prospects of development of medical genetics
}

\author{
Abildinova G.Zh. ${ }^{1}$ \\ ${ }^{1}$ National research center for maternal and child health \\ of the corporate fund "UMC», Astana,
}

J CLIN MED KAZ 2017; 3(45 SUPPL 3):8-10

\author{
МЕДИЦИНАЛЫҚ ГЕНЕТИКА ДАМУЫНЫҢ НӘТИЖЕЛЕРІ МЕН \\ БОЛАШАҒЫ \\ Абильдинова Г. Ж. \\ "UMC" Корпоративтік қорының Ана мен бала ұлттық гылыми орталығы, Астана, Казахстан
}

\author{
ИТОГИ И ПЕРСПЕКТИВЫ РАЗВИТИЯ МЕДИЦИНСКОЙ ГЕНЕТИКИ \\ Абильдинова Г.Ж.1 \\ 1 Национальный научный центр материнства и детства, Астана, Казахстан
}

\section{Введение}

Отделение клинико-генетической диагностики начала свою деятельность с 20 августа 2007 года. За прошедшее десятилетие были достигнуты определенные результаты, лаборатория является единственным научным подразделением в Республике Казахстан, где проводятся современные генетические исследования пациентов с врожденной и наследственной патологией, выполняются функции научно-консультативного и методического центра для послевузовского и постдипломного образования. Проводится подготовка врачей резидентов, переподготовка и повышение квалификации по специальности «Медицинская генетика».

Отделение активно участвует в подготовке научных кадров, на базе отделения подготовлены 4 магистра медицины и 2 доктора $\mathrm{PhD}$. Сотрудники отделения принимали активное участие в научно-исследовательской деятельности, опубликовано более 150 научных работ в журналах РК, ближнего и дальнего зарубежья, изданы 2 монографии «Система менеджмента качества в медицинских лабораториях», «Актуальные вопросы медицинской генетики». Отделение одним из первых в странах СНГ имеет сертификат аттестации на соответствие СТ PK ISO 15189-2015.

В отделении внедрены медико-генетическое консультирование, цитогенетические и молекулярно цитогенетические исследования (insituhybridization), молекулярно-генетические методы (ПДРФ анализ, MLPAметод). Лаборатория оснащена современным высокотехнологичным оборудованием. Сотрудники лаборатории прошли подготовку в странах ближнего и дальнего зарубежья (Россия, Литва, Израиль, Турция, Германия). В настоящее время проводятся научные исследования по изучению распространенности и структуре генетических заболеваний. Для оценки генетического груза популяции разработана информационно-аналитическая система «Үміт» для регистрации (Авторское право), систематизации и учета генетической патологии. База данных формировалась и формируется по обращаемости на основе медико - генетического консультирования новорожденных, их родителей, беременных и плодов врачом генетиком, также данных патологоанатомического вскрытия. Для систематизации выявленной патологии использовалась классификация ВОЗ МКБ 10. Класс XVII. При верификации генной патологии использовалась оксфордская база данных (Oxford Medical Databases). На сегодняшний день регистр включает в себя информацию более чем 4000 случаев наследственной и врожденной патологии.

Изучение разнообразия моногенной наследственной патологии у населения является важной составляющей генетико-эпидемиологического исследования популяции, позволяющее выделить частые и редкие наследственные заболевания, определить их базовые значения, выявить дифференциацию отдельных популяций, по спектру наследственных болезней и определить региональные или этнические особенности нозологического спектра.

\begin{tabular}{|c|c|c|c|c|c|c|}
\hline Таблица 1 & \multicolumn{6}{|c|}{$\begin{array}{l}\text { Спектр выявленной хромосомной } \\
\text { патологии }\end{array}$} \\
\hline Показания & \multicolumn{2}{|c|}{ Возрастной фактор } & \multicolumn{2}{|c|}{$\begin{array}{l}\text { Биохимические } \\
\text { маркеры }\end{array}$} & \multicolumn{2}{|c|}{$\begin{array}{l}\text { Ультразвуковые } \\
\text { маркеры }\end{array}$} \\
\hline Количество & 3222 & & 2315 & & 1005 & \\
\hline Норма & 3002 & $93,2 \%$ & 2239 & $96,7 \%$ & 912 & $90,8 \%$ \\
\hline Патология & 220 & $6,8 \%$ & 76 & $3,3 \%$ & 93 & $9,2 \%$ \\
\hline с/м Дауна & 119 & $3,7 \%$ & 31 & $1,4 \%$ & 34 & 3,3 \\
\hline с/м Эдвардса & 31 & $0,9 \%$ & 3 & 0,1 & 18 & 1,8 \\
\hline с/м Патау & 9 & 0,3 & 1 & 0,04 & 5 & 0,5 \\
\hline Половые & 19 & 0,6 & 5 & 0,2 & 13 & 1,3 \\
\hline Структурные & 28 & 0,9 & 25 & 1,1 & 18 & 1,8 \\
\hline Прочие & 14 & 0,4 & 11 & 0,5 & 5 & 0,5 \\
\hline
\end{tabular}


Наиболее действенными мерами профилактики наследственной патологии и врожденных пороков развития, осуществляемых в медико-генетических консультациях, являются мероприятия по пренатальной диагностике с последующим прерыванием беременности в случае выявления у плода летального или тяжелого порока развития.

В таблице 1 представлены результаты пренатального цитогенетического исследования. За истекший период проведено более 6000 цитогенетических исследований. Выявлено 389 случаев хромосомной патологии, процент выявляемости хромосомной патологии составил $6 \%$. Из материалов таблицы видно, что процент выявляемой хромосомной патологии превалирует при таких показаниях как возрастной фактор и ультразвуковые маркеры. Из 3222 беременных с возрастным фактором 35 лет и более хромосомная патология выявлена в 6,8\% случаях, при наличии ультразвуковых маркеров - 9,2\% случаях. Проведен анализ частоты и типов хромосомных нарушений. В структуре хромосомных аномалий преобладают несбалансированные хромосомные аномалии. Полученные результаты показывают, что среди зарегистрированных 425 случаев с синдромом Дауна, в 40\% патология обнаружена в пренатальном периоде в результате проведения инвазивной пренатальной диагностики.

Результаты цитогенетического исследования были сопоставлены с данными эхографического и биохимического скрининга. При ультразвуковом исследовании в первом триместре учитывали толщину воротниковой зоны; во II триместре -гиперэхогенный кишечник, двойной контур головы, изменение длины костей носа, многоводие, маловодие, задержка внутриутробного развития плода.

Самыми частыми показаниями для проведения инвазивных методов являлись: возраст старше 35 лет, ультразвуковые и биохимичесие маркеры.

Процент выявляемости хромосомной патологии составил в среднем 6\%. При анализе структуры хромосомных аномалий в 90\% случаев были обнаружены числовые аномалии, в 10\% случаях диагностирована структурная патология и в 9,3\% случаях диагностирован химерный клон.

Наибольший удельный вес в выявленной хромосомной патологии занимает синдром Дауна $-20 \%$, что объясняется высокой частотой данного синдрома в популяции.

Кариологическое исследование лимфоцитов периферической крови

Разработка вопросов эпидемиологии хромосомных болезней важна как с практической, так и с теоретической точки зрения. Выяснение частоты хромосомных болезней, в том числе синдрома Дауна, позволяет планировать объем медицинской помощи таким больным, соответственно, рассчитать затраты, необходимые для профилактики заболевания в исследуемом регионе. В этой связи, изучение особенностей распределения и структуры хромосомных болезней представляет актуальную научную задачу и имеет большое значение для практического здравоохранения. Повышение качества проспективной пренатальной диагностики создает научную основу для превентивных профилактических мероприятий по снижению хромосомных заболеваний в республике. Одним из ведущих в диагностике хромосомных заболеваний является цитогенетический метод исследования.

Популяционная распространенность хромосомных аномалий достигает около $1 \%$, но частота их значительно выше, если иметь ввиду хромосомные факторы при бесплодии, внутриутробных потерях и невынашивании беременности, при врожденных пороках развития, умственной отсталости и других формах нарушения развития, когда хромосомные нарушения являются отражением патологического процесса [3].

Проведено цитогенетическое обследование более 3500 детей с различными пороками развития и дизморфиями, в том числе детей с подозрением на болезнь Дауна. Аномалии кариотипа выявлены у 20\% детей. Структурные перестройки встречались редко $(7 \%)$ и представлены, в основном изменениями $4,5,8,10,13,14$ и 18 аутосом. Наиболее частая хромосомная патология - синдром Дауна $-20 \%$ и основную долю составили простые формы трисомии по 21 хромосоме -98 \%. Мозаичные формы кариотипа выявлены в 1,7\% случаев, робертсоновские транслокации в $0,5 \%$ случаев.

При проведении кариологического исследования в лимфоцитах периферической крови у супружеских пар с отягощенным акушерским анамнезом процент цитогенетических находок невелик (3,2\%). В основном патология представлена мозаичными вариантами половых хромосом, сбалансированными реципрокными и робертсоновскими транслокацими в системе аутосом 4, 9, $13,14,15,18,20,21$. При нарушении полового развития был выявлен синдром тестикулярной феминизации. Кроме того, отмечается высокий процент полиморфизма хромосом - увеличение гетерохроматиновых участков 9, 16 аутосом, увеличение спутников на акроцентрических хромосомах, экстремальное состояние Ү-хромосомы (значительное увеличение или укорочение гетерохроматиновых районов длинного плеча).

Число пациентов, обследованных по поводу бесплодия в браке, составило 2000 человек. В результате проведенного цитогенетического исследования у $4 \%$ женщин и $10 \%$ мужчин были обнаружены различные аномалии половых хромосом, как числовые, так и структурные аномалии хромосом: 45, ХО, 46,ХУt(7;17), 46,ХУt(9;20), 47, ХХУ.

Кариологическое исследование клеток костного мозга

В настоящее время известно, что ведущее место в патогенезе многих злокачественных новообразований отводится появлению клональных хромосомных маркеров. Характер мутаций определяет морфоцитохимические особенности и иммунофенотипом опухолевых клеток, отражающие уровень их дифференцировки.

Таблица 1 Хромосомные перестройки, характерные для гемабластозов

\begin{tabular}{|l|l|l|l|l|}
\hline ОМЛ & ОЛЛ & ХМЛ & ХЛЛ & МДС \\
\hline $\mathrm{t}(9 ; 22(\mathrm{q} 34 ; \mathrm{q} 11)$ & $\mathrm{t}(9 ; 22(\mathrm{q} 34 ; \mathrm{q} 11)$ & $\begin{array}{l}\mathrm{t}(9 ; 22) \\
(\mathrm{q} 34 ; \mathrm{q} 11)\end{array}$ & del (11)(q23) & $\begin{array}{l}\mathrm{t}(1 ; 3) \\
\text { (p36;q21) }\end{array}$ \\
\hline $\mathrm{t}(8 ; 21)(\mathrm{q} 22 \mathrm{q} 22)$ & $\mathrm{t}(8 ; 21)(\mathrm{q} 22 \mathrm{q} 22)$ & $\begin{array}{l}\mathrm{t}(3 ; 5) \\
(\mathrm{q} 26 ; \mathrm{q} 35)\end{array}$ & $\begin{array}{l}\text { del(5) } \\
(\mathrm{q} 22 ; \mathrm{q} 35)\end{array}$ & $\begin{array}{l}\text { del(18) } \\
\text { (q21 } \mathrm{ter})\end{array}$ \\
\hline $\begin{array}{l}\mathrm{t}(15 ; 17) \\
(\mathrm{q} 22 ; \mathrm{q} 21.1)\end{array}$ & $\mathrm{t}(4 ; 11)(\mathrm{q} 21 ; \mathrm{q} 23)$ & $\begin{array}{l}\mathrm{t}(5 ; 12) \\
(\mathrm{p} 13 \mathrm{q} 13)\end{array}$ & & inv 9 \\
\hline BCR/ABL & $\mathrm{t}(11 ; 21)(\mathrm{q} 23 ; \mathrm{q} 10)$ & & & del18p11.2 \\
\hline $\mathrm{t}(2 ; 4)(\mathrm{q} 35 ; \mathrm{q} 25)$ & $\mathrm{t}(12 ; 21)(\mathrm{p} 13 ; \mathrm{q} 22)$ & & & $-\mathrm{X}$ \\
\hline+8 & $\operatorname{inv} 9$ & & & $-\mathrm{Y}$ \\
\hline+21 & +9 & & & \\
\hline $\begin{array}{l}\text { der(4)t(1;4;5) } \\
(\mathrm{p} 36 ; \mathrm{q} 31 ; \mathrm{q} 21)\end{array}$ & +10 & & & \\
\hline & $\mathrm{t}(1 ; 19)(\mathrm{q} 23 ; \mathrm{p} 13)$ & & & \\
\hline & $\mathrm{t}(1 ; 8)(\mathrm{p} 36 ; \mathrm{q} 22)$ & & & \\
\hline & $\begin{array}{l}\text { der(1)t(1;1) } \\
(\mathrm{p} 36 ; \mathrm{q} 21)\end{array}$ & & & \\
\hline & $\mathrm{t}(5 ; 12)(\mathrm{p} 13 \mathrm{q} 13)$ & & & \\
\hline & & & & \\
\hline
\end{tabular}


Наличие той или иной аномалии кариотипа позволяет диагностировать и классифицировать формы лейкоза, судить о степени злокачественности опухоли (низкая, средняя, высокая) и в соответствии с этим выбирать соответствующую терапию и следить за ее эффективностью. Кроме того, известно, что специфические цитогенетические маркеры при некоторых формах лейкозов играют определяющую роль для уточнения диагноза, разработки тактики лечения, а также для прогнозирования течения заболевания у больных лейкозом.

Цитогенетическое исследование выполнено у 600 пациентов, 300 детей и подростков в возрасте от одного месяца до 18 лет и 300 взрослых. Нормальный кариотип выявлен в 7,3\% случаев. Чаще регистрировали кариотипы с эволюцией аномалий хромосом (41,5\%). В количественные и структурные перестройки вовлекались практически все хромосомы. Среди количественных перестроек чаще регистрировали трисомии хромосом 8, 21, 10 и 9. Хромосомные аномалии наблюдали в 31,6\% случаев. Среди структурных перестроек чаще встречались делеции и транслокации (33,9\% и 32,3\% соответственно). У взрослых пациентов в кариотипе превалировали моносомии, трисомий, маркерные хромосомы.

В сбалансированных структурных перестройках чаще принимали участие хромосомы $17,15,16,21,9,11$ и 8 , а в несбалансированных (делеции) - хромосомы 16, 11 и 12. В таблице 1 представлены основные хромосомные аномалии, характерные для гемабластозов.

Также необходимо отметить, относительно высокий процент клонов с гипердиплоидией (47-50 хромосом) (25\%), и наличие высокой гипердиплоидии (более 50 хромосом) в $14 \%$ случаев.

В лаборатории внедрены молекулярно-генетические исследования для мониторинга минимальной резидуальной болезни у пациентов с ХМЛ, находящихся в состоянии ремиссии. Молекулярный мониторинг экспрессии BCRABL является обязательным атрибутом контроля лечения хронического миелолейкоза. Достижение молекулярного ответа признано важным прогностическим фактором и показателем успешной терапии ингибиторами тирозинкиназ. Значение экспрессии $1 \%$ (IS) у пациентов с ПЦО является границей для сохранения цитогенетического ответа.

В развитии ХМЛ ключевую роль играет химерный ген BCR-ABL, образующийся в результате транслокации между хромосомами 9 и 22. Данный ген кодирует белок с молекулярной массой 210кДа, обладающий более высокой протеинкиназной активностью, чем продукт нормального протоонкогена ABL. B подавляющем большинстве лейкозов с транслокацией $\mathrm{t}(9 ; 22)$ в гене BCR разрывы локализуются на участке, обозначаемом M-BCR, и образующийся химерный ген BCR-ABL включает длинный фрагмент гена BCR, и в результате возникает характерный для ХМЛ белок Р210 Bcr/ Abl. И следует отметить, что белок Р210 имеет два варианта b3a2 и b2a2. Кроме того, разрывы могут локализоваться на одном из двух других типичных участков, называемых m-bcr и $\mu$-bcr. Разрывы в области m-bcr приводят к образованию химерного белка P190 Bcr/Abl. При локализации разрывов в m-bcr образуется более крупный белок - P230 Bcr/Abl. Необходимо отметить, что корреляционная связь между типом химерного белка (P210 Bcr/Abl, P190 Bcr/Abl, P230 $\mathrm{Bcr} / \mathrm{Abl)}$ и клинико-гематологической картиной лейкоза не является строгой. Кроме того, обнаружение транскриптов химерного гена необходимо для контроля полной ремиссии.
Обнаружение химерного транскрипта проведено у 25 пациентов. У $10 \%$ пациентов обнаружено наличие двух и трех транскриптов.

Миелопролиферативные заболевания представляют собой группу гематологических заболеваний, характеризующихся первичным расстройством кроветворных стволовых клеток, приводящим к росту одного или нескольких типов клеток крови. Для данных патологий характерно гиперклеточность костного мозга, повышение количества периферических эритроцитов,

\section{Таблища 2 Результаты диагностики}

миелопролиферативных заболеваний

\begin{tabular}{|l|l|l|}
\hline $\begin{array}{l}\text { Наименование } \\
\text { патологии }\end{array}$ & Кол-во & $\begin{array}{l}\text { Обнаружена мутация } \\
\text { V617F гена ЈАК2 }\end{array}$ \\
\hline $\begin{array}{l}\text { Хроническое } \\
\text { миелопролиферативное } \\
\text { заболевание }\end{array}$ & 61 & 25 \\
\hline Миелофиброз & 10 & 6 \\
\hline Эритроемия & 26 & 14 \\
\hline $\mathrm{Ph}(-)$ ХМПЗ & 5 & 5 \\
\hline
\end{tabular}

тромбоцитов, нейтрофилов. Заболевания могут осложняться тромбоэмболическими явлениями и кровотечениями. Выделяют несколько наиболее значимых заболеваний: полицитемия, тромбоцитемия, идиопатический миелофиброз и хронический миелолейкоз.

Наиболее важным критерием в диагностике миелопролиферативных заболеваний является мутация V617F в гене Jak2, который кодирует нерецепторную тирозинкиназу, участвующую в передаче сигнала от рецепторов цитокинов и факторов роста к ядру клетки и экспрессирован в ранних предшественниках гемопоэза [2]. Данная мутация определяется в 90-95\% случаев истинной полицитемии, 50-70 \% случаев эссенциальной тромбоцитемии и 40-50 \% случаев миелофиброза. Кроме того, определение мутации V617F гена JAK2 включено в перечень диагностических критериев ВОЗ для миелопролиферативных новообразований.

Как следует из данной таблицы, наиболее высокий процент встречаемости (50\%) мутации JАK2V617F определялся у пациентов с ХМПЗ, обнаружена она у 15 из 31 обследованных больных. В группе первичных больных, обследованных с целью дифференциальной диагностики $\mathrm{Ph}(-)$ ХМПЗ и заболеваний не гематологического профиля со схожей клинико-морфологической картиной, мутация выявлялась у $5(100 \%)$ из 5 больных, что позволило достоверно подтвердить диагноз.

Для дальнейшего развития лаборатория планирует проводить дальнейшую работу по:

1) оценке генетического груза врожденной и наследственной патологии РК,

2) выяснение механизмов нарушения репродуктивной функции мужчин и женщин, ассоциированные с хромосомной нестабильностью и мутациями генов,

3) изучение субтеломерных хромосомных перестроек в генезе недифференцированной умственной отсталости.

4) Совершенствованию цитогенетических и молекулярно-генетических методов для уточнения диагноза, разработки тактики лечения, а также для прогнозирования течения заболевания у больных лейкозом. 